\title{
Spectroscopic analysis of honey
}

\section{Yuriy Posudin}

\section{National University of Life and Environmental Sciences of Ukraine, Kyiv, Ukraine}

\section{Keywords:}

Honey

Botanical

Geographical

Origin

Quality

Adulteration

Spectroscopy

\section{Article history:}

Received 04.06.2016

Received in revised form 04.06 .2016

Accepted 01.09.2016

\section{Corresponding author:}

Yuriy Posudin

https://posudin.wordpress.com

\section{Abstract}

Introduction. The main objective of this investigation is to study the relationships of chemical composition, physical properties, botanical and geographical origin, and age of honey with its spectral parameters which can be used as taxonomic indices or indicators of honey state, quality and possible adulteration.

Materials and methods. Two non-destructive spectroscopic methods of honey authentication such as Near-Infrared Spectroscopy and Fluorescence Spectroscopy were used.

Results and discussion. The intensity of absorption spectra can be used as a criterion of geographical origin or age of honey.

The intensity of emission fluorescence spectra of honey depends on the geographical origin, its age, and on the type of honey.

The effect of temperature on the fluorescence intensity of honey demonstrated that the increasing of temperature provoked the decreasing of the fluorescence intensity. It was established the correlation between fluorescence properties of honey and the presence of water in it.

The reflectance spectra of honey samples in NIR part of the spectrum are characterized by a number of reflectance bands near 1,779 nm, 1,933 nm, and 2,290 $\mathrm{nm}$; the relative intensity of the spectral bands depends on the type and age of the sample. It is very informative to use spectral parameters of honey in NIR part of spectrum for the non-destructive detection of honey adulteration.

Conclusions. Methods of near-infrared and fluorescence spectroscopy can be explored in honeybreeding. Both spectroscopic techniques can be used for non-destructive, fast and precise diagnostics of honey. The chemical composition, physical properties, botanical and geographical origin, and age of honey are closely related to spectral parameters of honey which can be used as taxonomic indices or indicators of honey state, quality, and aduteration. 


\section{Introduction}

\section{Definition of Honey}

Honey, according to the accepted definition [Codex..., 1969], is the natural sweet substance produced by honey bees from the nectar of plants (Blossom Honey or Nectar Honey), or from secretions of living parts of plants, or excretions of plant sucking insects on the living parts of plants (Honeydew Honey), which the bees collect, transform by combining with specific secretions of their own, deposit, dehydrate, store and leave in the honeycomb to ripen and mature. Physical properties of honey are related to its state, age, presence of water and level of crystallization. All these factors affect the quality of honey.

\section{Composition of Honey}

Honey is a product with complex chemical composition: it contains plant pigments (carotenes, xanthophylls, chlorophyll), mineral substances, sugars, and various impurities.

The main components of honey are sugars, which are presented by fructose $(37.20 \%)$, glucose $(31.28 \%)$, sucrose $(1.31 \%)$, maltose $(7.31 \%)$, etc. [Je'Anne, 1991]. Blossom honey differs from honey dew by the values of simple sugars, disaccharides, higher sugars, acids, mineral salts and nitrogen content. The concentration of sugars can be used as a criterion of honey adulteration, which is provoked with the artificial addition of syrup, sucrose that is hydrolyzed with acids, starch or beetroot treacle in honey [Chudakov, 1967]. That is why precise quality evaluation of honey has long been the goal of many investigators and specialists who are related to honey-breeding [Vorwohl, 1984, 1990; Gonnet, 1986; Vakhonina et al., 1987; Dustmann, 1993; Mautz, 1993; Campos, 1994]. The composition of honey also reflects the contaminants which are present in the area of bee activity.

\section{Honey Quality}

High-quality honey can be distinguished by the aroma, taste and texture. Besides, good quality honey can not contain more than $18 \%$ water. High water level can cause the process of fermentation of honey and loss of its quality.

The quality of honey has been recognized by the European Directive (Council Directive, 1974) and the Food Standards Code (Codex Alimentarius standard, 1993). International Honey Commission, which was established in 1996, has revised the contents of these documents in recent years [Codex ..., 1993; Proposal ..., 1996; Bogdanov et al. 1999; Council Directive, 2001; Revised Codex ..., 2001] proposing specific quality parameters of honey and methods of its evaluation. The standard drafts include standards and methods for the determination of such quality factors as moisture, ash, acidity, HMF, apparent reducing sugars, apparent sucrose, diastase activity and water-insoluble matter. International honey standards for fructose/glucose content, the sucrose content and electrical conductivity were proposed. In addition, other quality factors, such as invertase activity, proline and specific rotation has been discussed.

The term non-destructive quality evaluation of honey means that the analysis of the honey sample and collection of its essential characteristics are carried out in such a way that physical and chemical properties of the sample are not changed.

\section{Spectroscopic Analysis of Honey}

Traditional methods of honey analysis are time-consuming and costly. That's why, there is a need for a new analytical technique that will enable non-destructive, fast and reproducible authentication of the botanical and geographic origins at low cost. 
Development of non-destructive methods, which are based on the analysis of the sample without any alterations of product attributes, present the problem of great practical significance. Spectroscopic methods occupy an important place among the comprehensive tests [Posudin, 2005]. These methods include the measurement of difference between input and output light signals during interaction of light with the sample (absorption, transmission, reflection, scattering, re-emission) and analysis of the dependence of this difference on the wavelength. Besides, spectroscopic methods are rather fast and precise. Effects of honey type, age, temperature, water content and degree of sugar adulteration on the spectral properties of honey can also be studied.

Certain spectroscopic methods that have been applied to honey control are mentioned in the literature: spectrophotometry [Yao and Chen, 1985; Yao and Fan, 1985; Salinas et al., 1994,a,b], optical activity measurement [Juan et al., 1992], atomic spectroscopy [Petrovic et al., 1994; Salinas et al., 1994], nuclear magnetic resonance [Ohmenhaeuser et al., 2013]. However, the fact is that honey presents a non-transparent and opaque substance; the application of the abovementioned methods requires either the dilution, or special preparation of the samples. Method of NMR spectroscopy makes it possible to detect very fine structural components, but this technique is very expensive, time consuming, spectra take long time to interpret.

Near-infrared (NIR) spectroscopy is a spectroscopic method that uses the near-infrared $(700 \mathrm{~nm}-2500 \mathrm{~nm})$ region of the electromagnetic spectrum.

It was shown that methods of near infrared spectroscopy (NIR) and mid infrared spectroscopy (MIR) can be applied for honey detection, particularly for quality control analysis, determination of botanical and geographical origin and detection of adulteration of honey. The principle, technology path, accuracy, influence factors, and the development trend are discussed [Tu et al., 2010].

Method of Fourier transform infrared spectroscopy (FT-IR) was used for the determination of water, glucose, fructose, sucrose, melezitose and monosaccharide content in honey as well as fructose/glucose ratio, glucose/water ratio, electrical conductivity, $\mathrm{pH}$ value and free acidity [Ruoff et al., 2006]. The results demonstrate that mid-infrared spectrometry is a valuable, rapid and non-destructive tool for the quantitative analysis of honey. More than 1600 samples of honey were analysed using FT-IR and reference methods to develop a partial least-square regression based calibration model for the major components of honey (sugars, proline, free acids, invertase, moisture, hydroxymethylfurfural, $\mathrm{pH}$ and electrical conductivity) [Lichtenberg-Kraag et al., 2002]. Fourier-transform infrared spectrometer was used to determine botanical origin of 144 samples of nine different unifloral honey types from different Croatian regions [Svečnjak et al., 2011].

The results of this study showed that FT-IR spectrometry provides reliable results, but also represents rapid, simple and cheap analytical tool in comparison to commonly used standard analytical methods.

Fourier transform infrared attenuated total reflectance (FT-IR ATR) spectroscopy was applied to 14 different samples of northeast Brazilian honey. The results showed that midinfrared spectrometry can be used as a screening method for the routine analysis of Brazilian honey, with the advantages of being rapid, non-destructive, and accurate [Almeida-Muradian et al., 2014].

Honey is a classic object of adulteration through the addition to natural honey such substances as sucrose, sugar, glucose, partial invert cane and corn syrups, and beet sugar, dextrin, starch, unripe honey, molasses, honeydew, and artificial sweeteners. Some samples of honey can be contaminated with heavy metals, pesticides, and antibiotics. Various 
spectroscopic methods of honey adulteration detection are used such as headspace-mass spectrometry, gas chromatography, combination of gas chromatography and mass spectrometry, terahertz time-domain spectroscopy, NIR spectroscopy, which can be used successfully to identify authentic honey from adulterated one [Posudin et al., 2015].

Fluorescence spectroscopy is a type of electromagnetic spectroscopy which analyzes fluorescence from a sample.

It was shown that unifloral honeys with very characteristic fluorescence spectra, such as chestnut honey, can be easily recognised using only one of the single spectra recorded. Honey types having less characteristic spectra, such as alpine polyfloral or lowland polyfloral honeys, need a combination of several spectra for a reliable authentication [Ruoff et al., 2005].

Front-face fluorescence spectroscopy, directly applied on honey samples, was used for the authentication of 11 unifloral and polyfloral honey types $(n=371$ samples $)$ previously classified using traditional methods such as chemical, pollen, and sensory analysis. This study indicates that front-face fluorescence spectroscopy is a promising technique for the authentication of the botanical origin of honey and may also be useful for the determination of the geographical origin within the same unifloral honey type [Ruoff et al., 2006]. This technique combined with chemometrics was used to classify honey samples according to their botanical origin. Synchronous fluorescence spectra of three monofloral (linden, sunflower, and acacia), polyfloral (meadow mix), and fake (fake acacia and linden) honey types (109 samples) were studied. The results demonstrated that this method is a valuable and promising technique for honey authentication [Lenhardt et al., 2014].

Fluorescence spectroscopy coupled with parallel factor analysis (PARAFAC) and Partial least squares Discriminant Analysis (PLS DA) were used for characterization and classification of honey [Lenhardt et al., 2015].

Method of fluorescence spectroscopy showed that while the major contributor to the fluorescence of cane sugar syrup is the reduced form of nicotinamide adenine dinucleotide, the fluorescence of honey is dominated by flavins. The difference in the synchronous fluorescence spectra of honey and cane sugar syrup could be used to monitor adulteration of honey by cane sugar syrup [Ghosh et al., 2005].

Fluorescence spectroscopy was used for quality control of honey, particularly to describe the types of honey and to distinguish the honey samples with added artificial sweeteners from natural ones [Nikolova et al., 2014].

The main objective of this investigation is to evaluate two non-destructive spectroscopic methods of honey authentication: Near-Infrared Spectroscopy and Fluorescence Spectroscopy.

\section{Materials and methods}

The samples of honeydew, which were used in these experiments, were taken from the collection of Bavarian Institute of Bee-Breeding (Erlangen, Germany) ${ }^{1}$, and the samples of honey - from different regions of Ukraine: Kyiv, Dnepropetrovsk, and Crimea. Samples with different percentage of sucrose were prepared in National University of Life and

\footnotetext{
${ }^{1}$ The samples of honeydew were presented by the courtesy of Dr. D. Mautz.
} 
Environmental Sciences of Ukraine, Kyiv, for obtaining useful information about adulteration of honey. Descriptions of all the samples are given in Table 1. The measurements of spectroscopic properties of Bavarian "Tanne" samples were performed in 1993, and of the Ukrainian honey samples in 1994.

Table 1

Samples of honey which were used in the experiments

\begin{tabular}{|c|c|c|c|}
\hline No & $\begin{array}{c}\text { Type } \\
\text { of Honeydew } \\
\end{array}$ & $\begin{array}{l}\text { Geographic } \\
\text { Origin }\end{array}$ & $\begin{array}{c}\text { Year } \\
\text { of Collection }\end{array}$ \\
\hline 1 & Abies alba, Schwarzwald ("Tanne") & Germany, Bavaria & 1989 \\
\hline 2 & " & “ & 1992 \\
\hline \multirow[t]{2}{*}{3} & $\begin{array}{l}\text { Abies alba, Bayerischerwald } \\
\text { ("Tanne") }\end{array}$ & " & 1990 \\
\hline & Type of Honey & $\begin{array}{l}\text { Geographical } \\
\text { Origin }\end{array}$ & $\begin{array}{l}\text { Year of } \\
\text { Collection }\end{array}$ \\
\hline 4 & Monofloral, Acacia & Ukraine, Crimea & 1993 \\
\hline 5 & Monofloral, Sunflower & “ & " \\
\hline 6 & Polyfloral, Esparcet-Rape-Acacia & “ & “ \\
\hline 7 & Polyfloral, Sage-Lavender & “ & " \\
\hline \multirow[t]{2}{*}{8} & Polyfloral, Sonchus-Buckwheat & “ & “ \\
\hline & Sunflower & " & " \\
\hline \multirow[t]{2}{*}{9} & Acacia & Ukraine, & \\
\hline & " & Verkhniodniprovsk & 1993 \\
\hline 10 & $"$ & $\begin{array}{l}\text { Ukraine, } \\
\text { Pavlivka }\end{array}$ & " \\
\hline 11 & $"$ & Ukraine, Motronivka & " \\
\hline 12 & $"$ & Ukraine, Vodiane & “ \\
\hline 13 & " & $\begin{array}{l}\text { Ukraine, } \\
\text { Didove }\end{array}$ & “ \\
\hline 14 & " & Ukraine, Andriivka & “ \\
\hline 15 & " & $\begin{array}{c}\text { Ukraine, } \\
\text { Malyi Bukryn } \\
\end{array}$ & “ \\
\hline 16 & " & $\begin{array}{c}\text { Ukraine, } \\
\text { Kyiv }\end{array}$ & " \\
\hline 17 & Lime-Tree & “ & 1996 \\
\hline 18 & Multiherbal Collection & “ & " \\
\hline
\end{tabular}

\section{Instrumentation}

The spectra of absorption and reflection of honey in the ultraviolet and visible part of the spectrum were measured with spectroscopic complex KSVU-23 ("LOMO", Russia), which was equipped with a double monochromator, diffraction gratings, and computer.

The investigation of fluorescence spectra of honey was performed with the spectrofluorometer SDL-2 ("LOMO", Russia) in the regime of photon counting. The spectral range during these measurements was $200-700 \mathrm{~nm}$; the errors of measurement were $2 \mathrm{~nm}$ for intensity of the bands and $5 \mathrm{~nm}$ for half-width of the bands. 
The reflectance spectra in the near-infrared (NIR) part of spectrum $(1,620-2,320 \mathrm{~nm})$ were measured with analyzer Model 4250 ("Pacific Scientific", USA). This analyzer has three ranges: $1,620-1,800 \mathrm{~nm}, 1,890-2,115 \mathrm{~nm}$, and 2,050-2,320 nm. Reproducibility of the results was better than $0.015 \mathrm{~nm}$. The NIR spectrum was estimated as the dependence of optical density $D=\log (1 / R)$ on the wavelength $\lambda$ (where $R$ is reflection coefficient). All measurements were performed at room temperature.

\section{Result and discussion}

\section{Results of Spectroscopic Analysis of Honey}

The absorption spectra of honeydew ("Tanne") in ultraviolet and visible parts of the spectrum are presented in Figure 1. A certain shoulder near $250-275 \mathrm{~nm}$ is standing out against the background which is decreasing monotonously from 200 to $700 \mathrm{~nm}$. The presence of the shoulder in absorption (reflectance) spectra of honey testifies the participation of several honey components in formation of absorption (reflectance) spectra in the ultraviolet and visible parts of the spectrum. The intensity of absorption can be used as a criterion of geographic origin or age of honey.

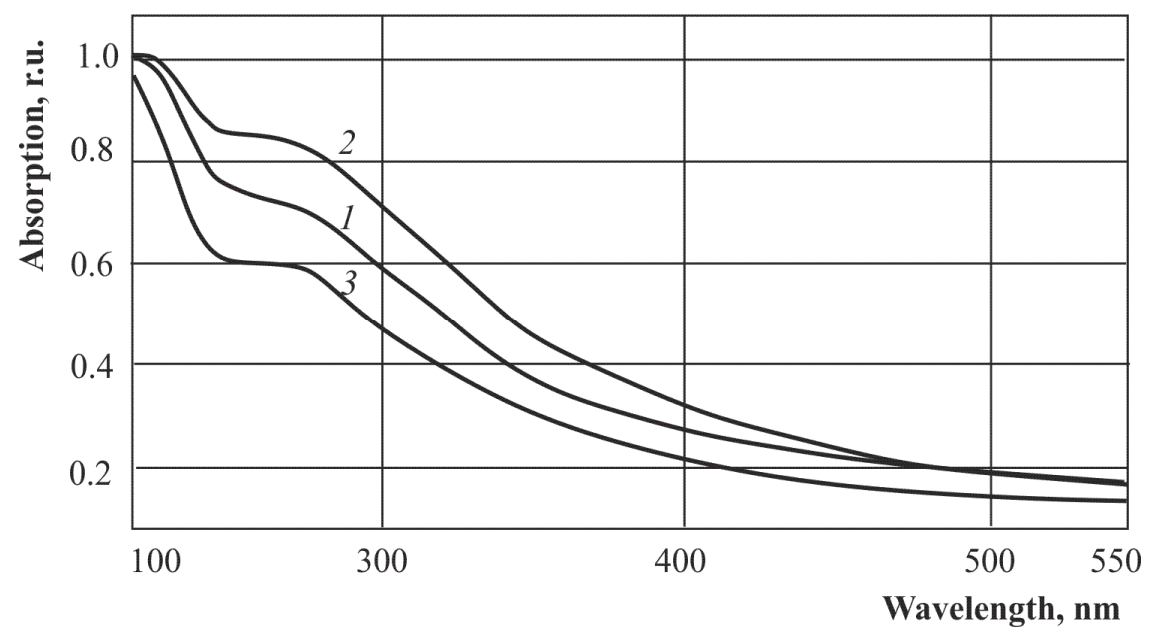

Figure 1. Absorption spectra of honey in ultraviolet and visible parts of spectrum: 1 - Schwarzwald "Tanne", 1989; 2 - Schwarzwald "Tanne", 1992;

3 - Bayerischer "Tanne", 1990

[Posudin et al., 1995]

The excitation fluorescence spectra of honeydew were investigated for different wavelengths of fluorescence emission (440 nm, $560 \mathrm{~nm}$, and $575 \mathrm{~nm}$ ).

The emission fluorescence spectra of honeydew are characterized by a broad band (about 100-150 nm); the spectral position of its maximum depends on the wavelength of excitation. These maxima are located near $420 \mathrm{~nm}\left(\lambda_{\text {exc }}=350 \mathrm{~nm}\right), 480 \mathrm{~nm}\left(\lambda_{\mathrm{exc}}=400 \mathrm{~nm}\right)$, and $510 \mathrm{~nm}\left(\lambda_{\mathrm{exc}}=450 \mathrm{~nm}\right)$. The maximal intensity of emission takes place during excitation in the ultraviolet part of the spectrum. The fluorescence intensity of honeydew depends on the geographical origin and its age. Typical fluorescence emission spectra of honeydew are presented in Figure 2. 


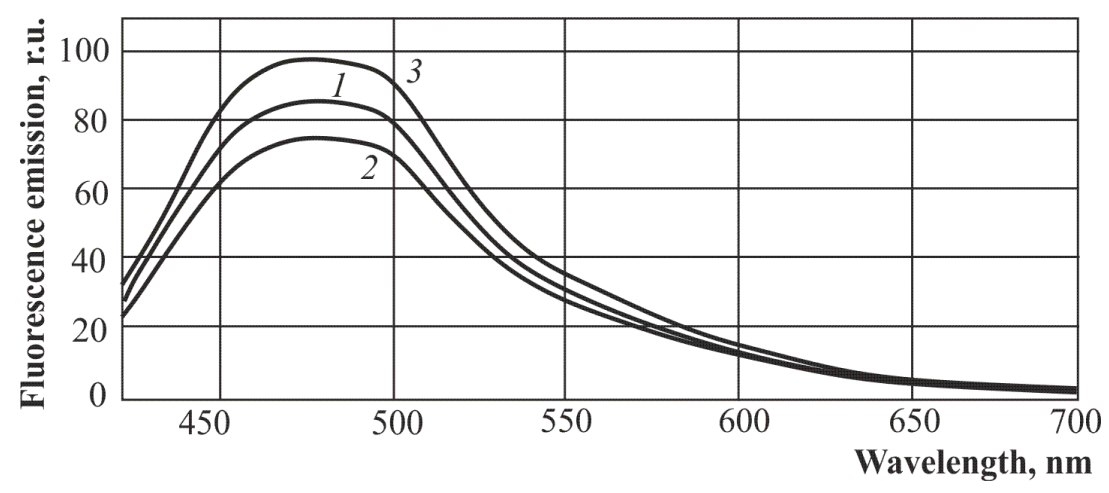

Figure 2. Fluorescence emission spectra of honey (samples N1-N3).

Wavelength of excitation $400 \mathrm{~nm}$

[Posudin et al, 1995]

The fluorescence intensity of honey also depends on the type of honey (Table 2); the samples of the same type of honey (Acacia), which were collected from different parts of one region and of one age, demonstrated quasi equal intensity of fluorescence, but this intensity depends on the age of honey (Table 3 ).

Table 2

Dependence of fluorescence intensity of honey on the geographic origin

\begin{tabular}{|c|l|c|}
\hline $\begin{array}{c}\text { Number of sample } \\
\text { (From Table 1) }\end{array}$ & \multicolumn{1}{c|}{$\begin{array}{c}\text { Type } \\
\text { of honey }\end{array}$} & $\begin{array}{c}\text { Fluorescence } \\
\text { Intensity }\end{array}$ \\
\hline 4 & Monofloral, Acacia & $0.29 \pm 0.064$ \\
\hline 5 & Monofloral, Sunflower & $0.48+0.088$ \\
\hline 6 & Polyfloral, Esparcet-Rape-Acacia & $0.38 \pm 0.031$ \\
\hline 7 & Polyfloral, Sage-Lavender & $0.69 \pm 0.096$ \\
\hline 8 & $\begin{array}{l}\text { Polyfloral, Sonchus-Buckwheat- } \\
\text { Sunflower }\end{array}$ & $0.43 \pm 0.045$ \\
\hline \multicolumn{2}{|l}{} \\
\hline
\end{tabular}

Dependence of fluorescence intensity on the geographic origin

Table 3 and year of collection of honey

\begin{tabular}{|c|l|c|c|}
\hline $\begin{array}{c}\text { Number of Sample } \\
\text { (From Table 1) }\end{array}$ & $\begin{array}{c}\text { Geographical } \\
\text { Origin }\end{array}$ & Year & Year \\
\hline & & $\mathbf{1 9 9 3}$ & $\mathbf{1 9 9 4}$ \\
\hline 9 & Verkhniodniprovsk & $0.30 \pm 0.08$ & $0.53 \pm 0.07$ \\
\hline 10 & Pavlivka & $0.21 \pm 0.05$ & $0.68 \pm 0.07$ \\
\hline 12 & Vodiane & $0.31 \pm 0.09$ & $0.82 \pm 0.16$ \\
\hline 13 & Didove & $0.34+0.10$ & $0.44 \pm 0.03$ \\
\hline 14 & Andriivka & $0.28+0.09$ & $0.50 \pm 0.02$ \\
\hline 15 & Malyi Bukryn & $1.28+0.06$ & $2.05 \pm 0.09$ \\
\hline
\end{tabular}


The dependence of intensity, half-width, and spectral position of fluorescence spectra on the wavelength of excitation and emission means the participation of several fluorophores in formation of fluorescence spectra of honey.

The effect of temperature on the fluorescence intensity of honey is demonstrated in Figure 3.

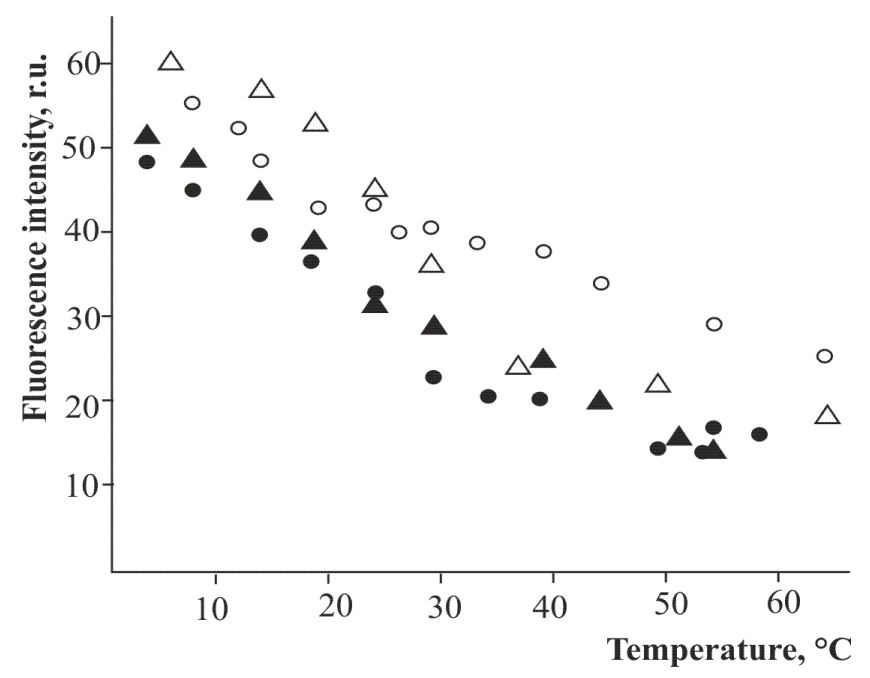

Figure 3. Dependence of fluorescence intensity of honey on the temperature.

- o-- monofloral, acacia, sample N4;

- $\mathbf{\Delta}$ - - monofloral, sunflower, sample N5;

$-\Delta$ - - polyfloral, sage-lavender, sample N7;

-•- - polyfloral, sonchus-buckwheat-sunflower, sample N8

[Posudin et al., 1995]

It is shown that the increasing of temperature provokes the decreasing of the fluorescence intensity.

The correlation between fluorescence properties of honey and the presence of water in it was also investigated. The quantity $W$ of water was estimated with the refractometric method according to the following relation [Aganin, 1989]:

$$
W=400\left[1.538-n\left(20^{\circ} \mathrm{C}\right)\right]
$$

where $n$ is the coefficient of refraction.

The results of these measurements are presented in Table 4 .

The coefficients of correlation were calculated for polyfloral honey $(r=-0.96)$ and monofloral honey $(r=-0.87)$. This strong negative correlation between the presence of water in honey and fluorescence intensity can be used for quality evaluation of honey. The reflectance spectra of honey samples in NIR part of the spectrum are characterized by a number of reflectance bands near $1,779 \mathrm{~nm}, 1,933 \mathrm{~nm}$ and 2,290 nm; the relative intensity of the spectral bands depends on the type and age of the sample (Figure 4). The samples taken from different parts of the same geographic region produced the same shape of the reflectance spectra, which were distinguished by the intensity of spectral bands only (Figs.5 and 6). However, the samples that were taken from different geographic zones demonstrated different shapes (Figs. 4 and 5). 
Table 4

Results of estimation of quantity $W$ of water by fluorescence and refractometric methods

\begin{tabular}{|c|c|c|c|c|c|}
\hline $\begin{array}{c}\text { Index of } \\
\text { Refraction } \\
\text { (n) }\end{array}$ & $\begin{array}{c}\text { Quantity } \\
\text { of Water } \\
\text { (W) }\end{array}$ & $\begin{array}{c}\text { Fluorescence } \\
\text { Intensity } \\
\text { (I) }\end{array}$ & $\begin{array}{c}\text { Index of } \\
\text { Refraction } \\
\text { (n) }\end{array}$ & $\begin{array}{c}\text { Quantity } \\
\text { of Water } \\
\text { (W) }\end{array}$ & $\begin{array}{c}\text { Fluorescence } \\
\text { Intensity } \\
\text { (I) }\end{array}$ \\
\hline & $\begin{array}{c}\text { Sage- } \\
\text { Lavender, } \\
\text { Sample N7 }\end{array}$ & & & Acacia, & \\
Sample N4 & \\
\hline 1.4961 & 16.76 & 2.98 & 1.4976 & 16.16 & 1.45 \\
\hline 1.4835 & 21.80 & 2.22 & 1.4785 & 23.80 & 1.28 \\
\hline 1.4711 & 26.80 & 1.52 & 1.4651 & 29.20 & 0.96 \\
\hline 1.4651 & 29.20 & 1.34 & 1.4565 & 32.60 & 0.88 \\
\hline 1.4420 & 37.50 & 0.92 & 1.4282 & 44.00 & 0.70 \\
\hline 1.4222 & 46.40 & 0.78 & 1.4082 & 51.90 & 0.64 \\
\hline 1.4061 & 52.80 & 0.74 & 1.3871 & 60.40 & 0.62 \\
\hline 1.3849 & 61.20 & 0.66 & 1.3600 & 71.20 & 0.50 \\
\hline 1.3650 & 68.20 & 056 & 1.3500 & 75.20 & 0.32 \\
\hline 1.3489 & 75.60 & 0.42 & 1.3380 & 80.00 & 0.24 \\
\hline 1.3380 & 80.00 & 0.34 & - & - & - \\
\hline
\end{tabular}

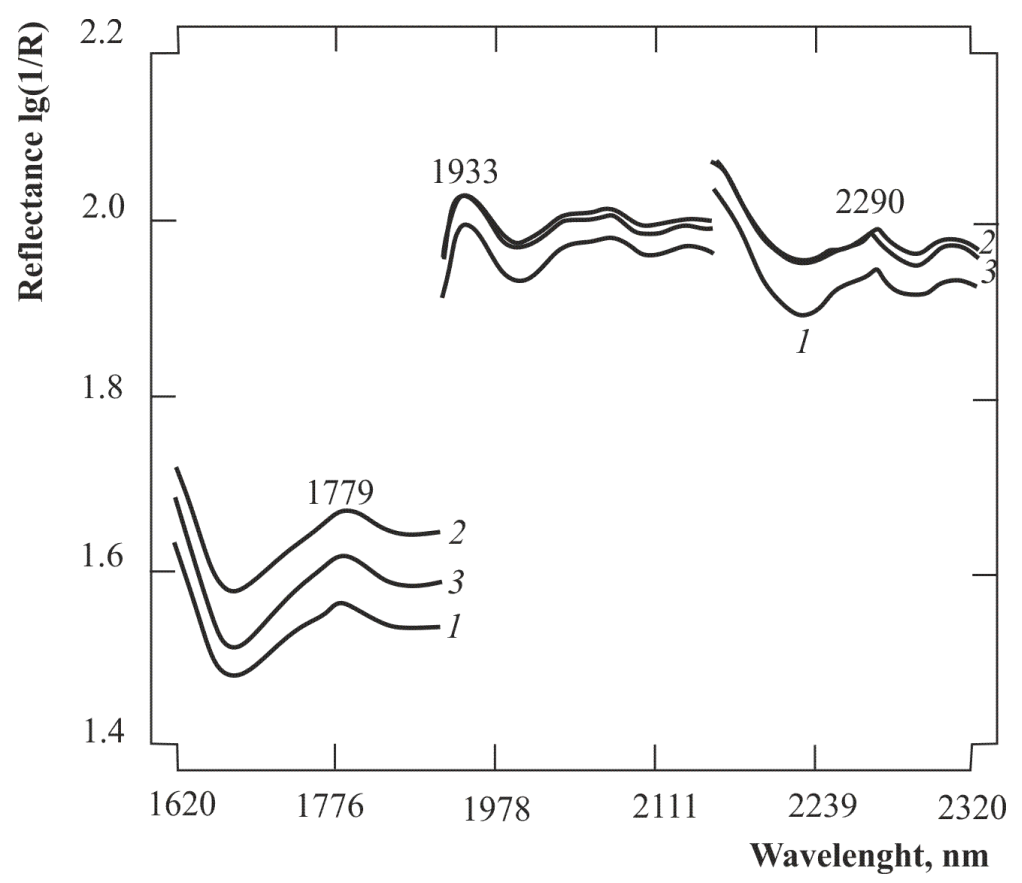

Figure 4. Reflectance spectra of honey in near-infrared part of spectrum (samples N 1-3)

[Posudin et al., 1995] 


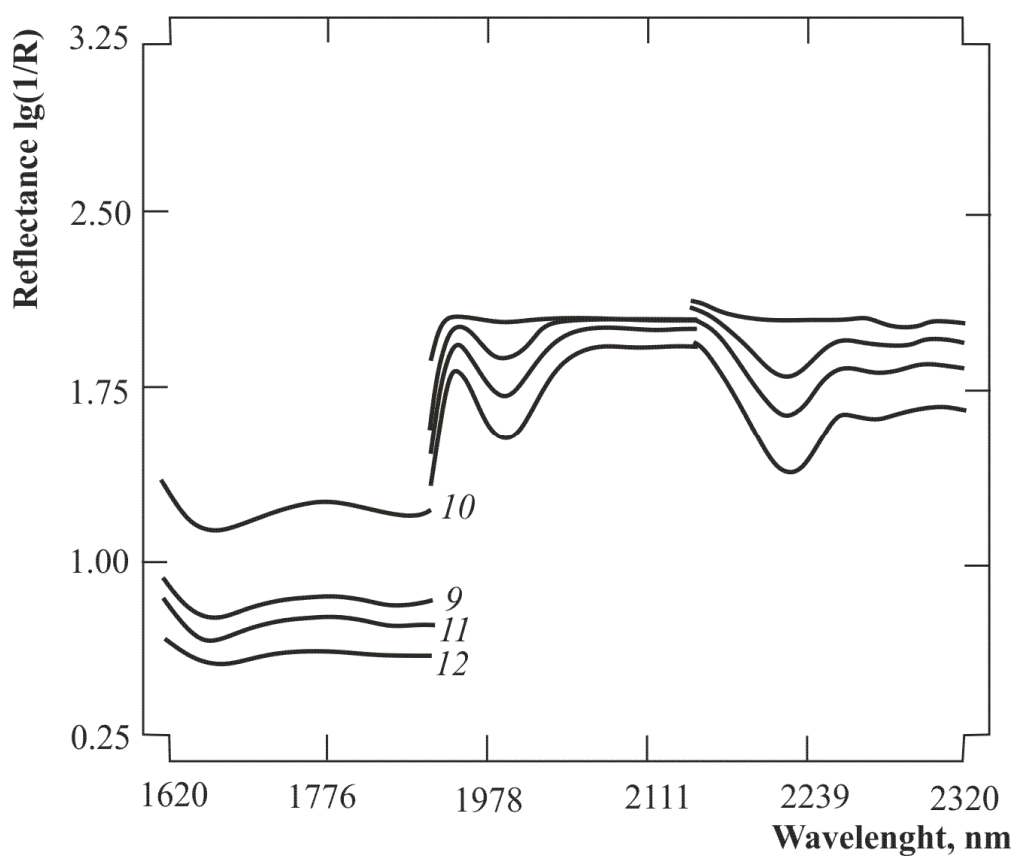

Figure 5. Reflectance spectra of honey in near-infrared part of spectrum (samples N 9-12) [Posudin et al., 1995]

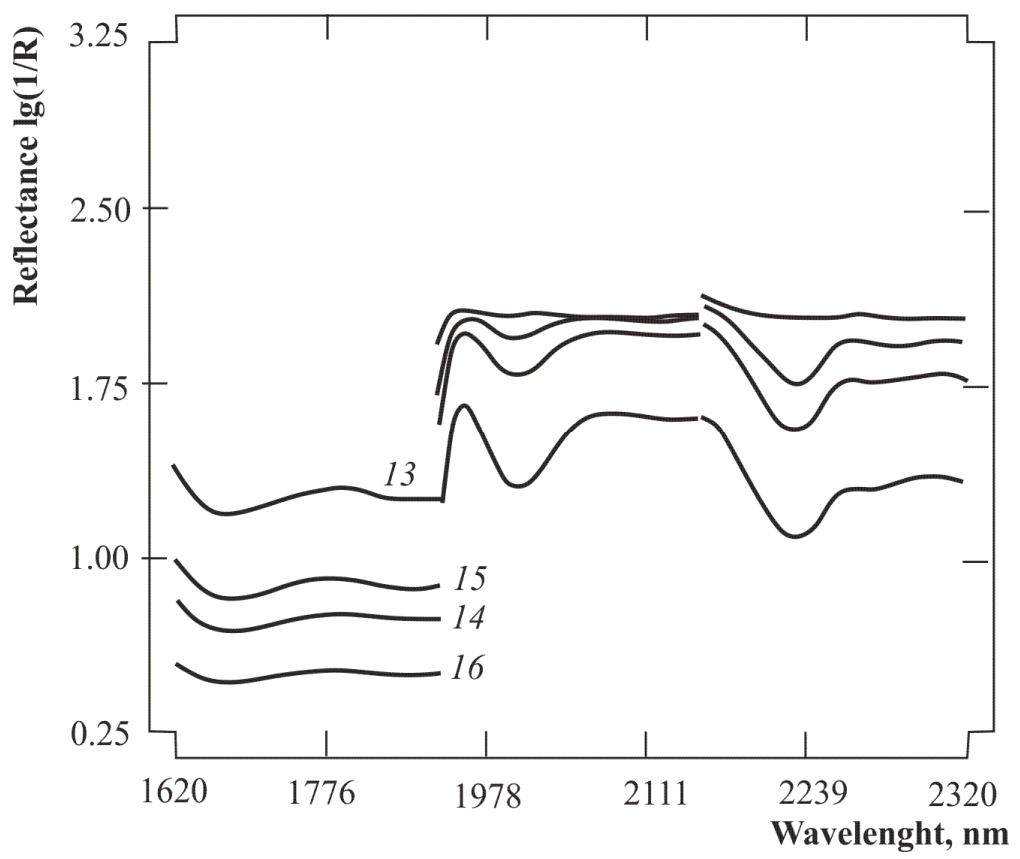

Figure 6. Reflectance spectra of honey in near-infrared part of spectrum (samples N 13-16) [Posudin et al., 1995] 


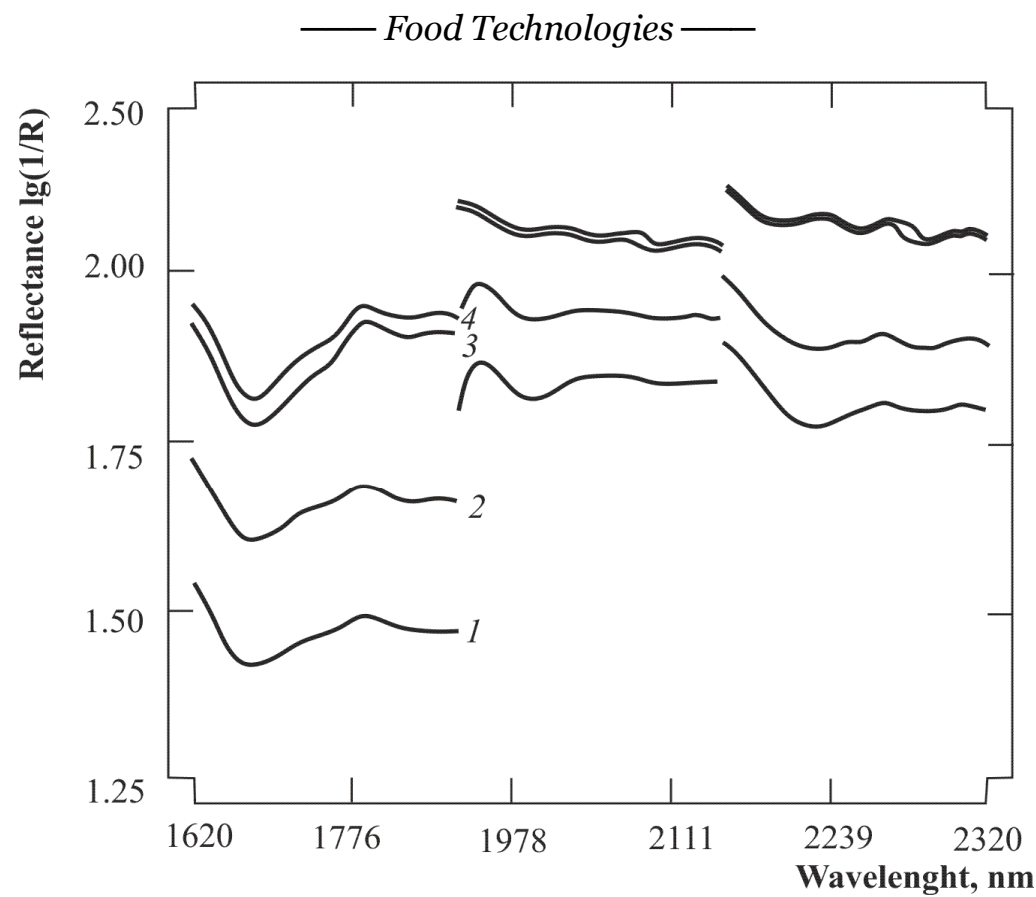

Figure 7. Dependence of reflectance spectra of lime-tree honey (sample $N$ 17) in near-infrared part of spectrum on the concentration of sucrose which was artificially added to honey: 1 - natural honey: $2-20 \%$ sucrose; $3-40 \%$ sucrose; $4-60 \%$ sucrose [Posudin et al., 1995]

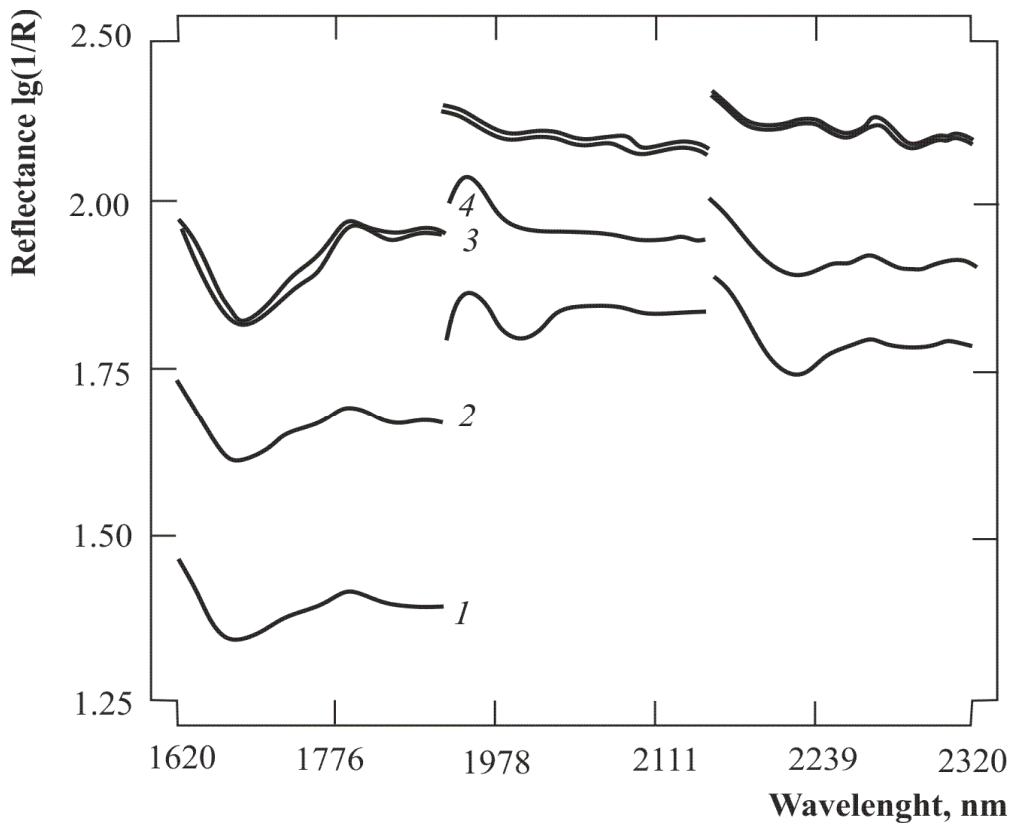

Figure 8. Dependence of reflectance spectra of multiherbal honey (sample $\mathrm{N} 18$ ) in nearinfrared part of spectrum on the concentration of sucrose which was artificially added to honey:

1 - natural honey: $2-20 \%$ sucrose; $3-40 \%$ sucrose; $4-60 \%$ sucrose [Posudin et al., 1995] 
It is very informative to use spectral parameters of honey for the non-destructive detection of honey adulteration. Figures 7 and 8 demonstrate the evolution of the reflectance spectra for the samples with different concentration of sucrose, which was artificially added to honey from lime-tree and multiherbal collection respectively. The curves "reflectance versus sucrose concentration" which are presented in Figure 9, can be used for quantitative estimation of honey adulteration. The accuracy limits in these experiments did not exceed $5 \%$.

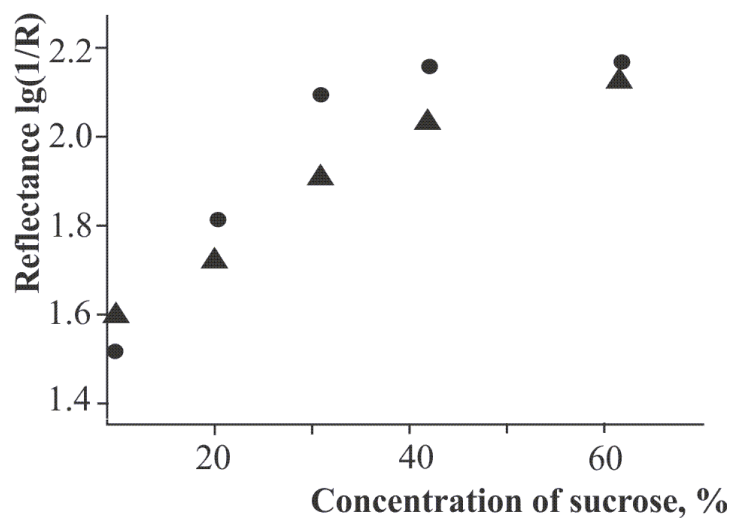

Figure 9. Dependence of reflectance of honey on the concentration of sucrose.

Wavelength is $1,779 \mathrm{~nm}$.

- $\mathbf{\Delta}$ - - lime-tree honey;

-_ - multiherbal honey

[ Posudin et al., 1995]

Thus, honey is characterized by certain spectral properties in ultraviolet, visible, and near-infrared parts of the spectrum, which are related to its ability to absorb, transmit, reflect and re-emit optical radiation. The chemical composition and physical properties of honey are closely related to its spectral parameters, which can be used as taxonomic indices or indicators of honey state and quality.

\section{Conclusion}

Methods of near-infrared and fluorescence spectroscopy can be explored in honeybreeding. Both spectroscopic techniques can be used in principle for non-destructive, fast and precise diagnostics of honey. The chemical composition, physical properties, botanical and geographic origin, and age of honey are closely related to spectral parameters of honey which can be used as taxonomic indices or indicators of honey state and quality.

The near-infrared reflectance spectroscopy and fluorescence spectroscopic methods are simple and inexpensive; they do not require particular sample preparation or special qualification of laboratory personnel. Both spectroscopic methods provide useful information about the adulteration of honey.

Acknowledgements. The author thanks Mautz D., Polishuk V.P., Bulavin S.P. and Istomina V.A for providing the of honey samples, research assistance and discussion of results. 


\section{References}

1. Aganin A.V. (1989), Sanitary Expertise of Honey, Saratov Agr. Inst. Publ., Saratov.

2. Almeida-Muradian L.B., Sousa R.J., Barth O.M., Gallmann P. (2014), Preliminary data on Brazilian monofloral honey from the northeast region using FT-IR ATR spectroscopic, palynological, and color analysis, Quim. Nova, 37(4).

3. Bogdanov et al. (1999), Honey quality and international regulatory standards: review by the International Honey Commission, Bee World, 80(2).

4. Campos M.G. (1994), Controle de qualidade e tipificacao de meis, Apicultor, 2(6), pp. 19-24.

5. Chudakov, V.G. 1967. Composition and Properties of Sugar Honey and Methodics of Detection of this Adulteration, Moscovsky Rabochy, Moscow

6. (1993), Codex Alimantarius Standard for Honey, Ref. Nr. CL 1993/14-SH FAO and WHO, Rome

7. Codex Alimentarius Comission CAS/RvS 12/1969, Recommended European Regional Standard for Honey, FAO/WHCXed., Rome. Codex Stan 12-1981, Rev.1 (1987), Rev.2 (2001).

8. (2002), Council Directive 2001/110/EC of 20 December 2001 relating to honey, Official Journal of the European Communities, No L 10/47 2002.

9. Dustmann J.H. (1993), Honey, quality and its control, American Bee Journal. 133(9), pp. 648-651.

10. Ghosh N., Verma Y., Majmder S.K., Gupta P.K. (2005), A Fluorescence Spectroscopic Study of Honey and Cane Sugar Syrup, Food Sci. Technol. Res., 11(1), pp. 59-62.

11. Gonnet, M. (1986), L'analyse des miels. Description de queiques methodes de controle de la qualite. Bulletin-Technique-Apicole, 13(1), pp. 17-36.

12. Je'Anne, F. (1991), Le Miel. Definition, origines composition et proprietes. ButtetinTechnique-Apicole, 18(3), 76, pp. 205-210.

13. Juan T. Conchello M.P., Tello M.L., Perez-Arquille C., Herrera A. (1992), Rotation especifica espcetro glucidico de mieles de Zaragoza, Alimentaria, 28(232), pp. 75-78.

14. Lenhardt L., Brob R., Zeković I., Dramićanin T., Dramićanin M.D. (2014), Determination of the Botanical Origin of Honey by Front-Face Synchronous Fluorescence Spectroscopy, Applied Spectroscopy, 68(5), pp. 557-563.

15. Lenhardt L., Brob R., Zeković I., Dramićanin T., Dramićanin M.D. (2015), Fluorescence spectroscopy coupled with PARAFAC and PLS DA for characterization and classification of honey, Food Chemistry, 175, pp. 284-291.

16. Lichtenberg-Kraag D., Hedtke C., Bienefeld K. 2002. Infrared spectroscopy in routine quality analysis of honey, Apidologie, 33(3)

17. Mautz D., Rosenkranz P., Schaper F. (1993), Die Tatigkeit der B. Landesanstalt fur Bienenzucht. Erlangen im Jahre 1991/92, Imkerfreund, 9, pp. 1-29.

18. Nikolova Kr., Eftimov T., Aladjadjiyan A. (2014), Fluorescence Spectroscopy as Method for Quality Control of Honey, Advances in Research, 2(2), pp. 95-108.

19. Ohmenhaeuser M., Monakhova Y.B., Kuballa T., Lachenmeier D.W. (2013), Qualitative and Quantitative Control of Honeys Using NMR Spectroscopy and Chemometrics, ISRN Analytical Chemistry, 2013, Article ID 825318.

20. Petrovic Z.T., Mandic M.I., Grgic J., Grgic Z. (1994), Ash and chromium levels of some types of honey, Zeitschrift fur Lebensmittel-Untersuchung und Forschung, 198(1), pp. 36-39.

21. Posudin Yu. (1995), Biophysics, Urozhaj, Kyiv 
22. Posudin Yu.I. (2005), Methods of Nondestructive Quality Evaluation of Agricultural and Food Products, Aristey, Kyiv

23. Posudin Yu.I., Polishuk V.P., Bulavin S.P., Istomina V.A. (1995), Spectroscopic methods of honey investigation, Visnyk agrarnoi nauky, 6, pp. 78-82

24. Posudin Yuriy, Peiris K.H.S., Kays Stanley J. (2015), Non-destructive detection of food adulteration to guarantee human health and safety, Ukrainian Food Journal, 4(2), pp. 207-260, 344, 353.

25. Proposal for a directive of the European council relating to honey, EU document 96/0114, 1996.

26. Revised Codex Standard for Honey. Codex Stan 12-1981, Rev. 1 (1987), Rev.2 (2001).

27. Ruoff K., Karoui R., Dufour E., Luginbühl W., Bosset J. O., Bogdanov S., Amadò R. (2005), Authentication of the Botanical Origin of Honey by Front-Face Fluorescence Spectroscopy. Preliminary Study, J. Agric. Food Chem., 53, pp. 1343-1347.

28. Ruoff K., Luginbühl W., Künzli R., Bogdanov S., Bosset J.O., von der Ohe K., von der Ohe W., Amadò R. (2006), Authentication of the Botanical and Geographical Origin of Honey by Front-Face Fluorescence Spectroscopy, J. Agric. Food Chem., 54(18), pp. 6858-6866.

29. Ruoff K., Iglesias M. T., Luginbühl W., Bosset J. O., Bogdanov S., Amadò R. (2006), Quantitative Analysis of Physical and Chemical Measurands in Honey by Mid-Infrared Spectroscopy, Eur. Food Res. Technol., 223, pp. 22-29.

30. Salinas F., Deespinosa V.M., Osorio E., Lozano M. (1994)a, Determination of mineral elements in honey from different floral origins by flow-injection analysis coupled to atomic spectroscopy, Revista Espanola De Ciencia Y Technologia De Ailmentos, 34(4), pp. 441-449.

31. Salinas F., Espinosa-Mansilla A. and Berzas-Nevado J.J. (1994)b, Simultaneous determination of sulfathiazole and oxytetracycline in honey by derivative spectrophotometry, Microchemical Journal, 43(3), pp. 244-252.

32. Svečnjak L., Biliškov N., Bubalo D., Barišić D. (2011), Application of Infrared Spectroscopy in Honey Analysis, Agriculturae Conspectus Scientificus, 76(3), pp. 191195.

33. Tu Z.H., Zhu D.Z., Ji B.P., Meng C.Y., Wang L.G., Qing Z.S. (2010), Progress in quality analysis of honey by infrared spectroscopy, Guang Pu Xue Yu Guang Pu Fen $X i, 30(11)$, pp. 2971-5.

34. Vakhonina T.V., Levina L.P. and Bondareva K.M. (1987), Quality of honey-pollen products, Pchelovodstvo, 8, pp. 28-29.

35. Vorwohl G. (1984), Honey and other hive products, and their quality control, Proc. of the Third Intern. Conf. on Apiculture in Tropical Climates, Nairobi, Kenya, 5-9 Nov. 1984, pp. 169-170.

36. Vorwohl G. (1990), Honigquatitatskontrolle und Honigqualitatskriterien in der Bundesrepublik, Bienenvater, 111(11), pp. 391-398.

37. Yao C., Chen L. (1985), Determination of traces of lead in honey by spectrophotometry with tetra(p-trimethylammoniumphenyl-porphine, Shipin-Yu-Fajiqo-Gongue, 6, pp. $38-41$.

38. Yao C., Fan C. (1985), Determination of zinc in honey by spectrophotometry with 5,10, 15, 20-tetrakis (4-trimethylammoniophenyl) porphine, Shipin-Yu-Fajiao-Gongue, 2, pp. 17-20. 